\title{
Nineteenth-Century Experimentation and the Role of Indigenous Foods in Australian Food Culture
}

\author{
Barbara Santich
}

In its periodic quest for culinary identity, Australia automatically looks to its indigenous ingredients, the foods that are native to this country. 'There can be little doubt that using an indigenous product must qualify a dish as Australian', notes Stephanie Alexander (357). Similarly, and without qualification, Cherikoff states that 'A uniquely Australian food culture can only be based upon foods indigenous to this country' (14), although, as Craw remarks, proposing Australian native foods as national symbols relies more upon their association with 'nature' and geographic origin than on common usage (46). Notwithstanding the lack of justification for the premise that national dishes are, of necessity, founded on ingredients native to the country - after all, Italy's gastronomic identity is tied to the non-indigenous tomato, Thailand's to the non-indigenous chili- the reality is that Australians do not eat indigenous foods in significant quantities. The exceptions are fish, crustaceans and shellfish from oceans, rivers and lakes, most of which are unarguably unique to this country. Despite valiant and well-intentioned efforts today at promoting and encouraging the consumption of native resources, bush foods are not harvested or produced in sufficient quantities for them to be a standard component of Australian diets, nor are they generally accessible. Indigenous foods are less relevant to Australian identity today than lamb and passionfruit, both initially imported and now naturalised. In the nineteenth century, however, and particularly outside the major cities, indigenous ingredients represented a valued resource. This paper examines nineteenth-century experimentation with indigenous foods and argues that it offers a model for the incorporation of indigenous foods into contemporary Australian food culture.

One source of blame for this unpatriotic lack of appetite for native foods is commonly laid on the attitudes of European settlers who reputedly overlooked or rejected out of hand the foods that, for millennia past, had sustained the original inhabitants, just as they saw Aboriginal people as primitive and inferior. According to Beckett, the Europeans' low opinion of indigenous inhabitants resulted in their losing 'whatever chance they might have had to really learn about the land' (Beckett 8). Many examples testify to their dismissal of indigenous ingredients. 'The list of esculent vegetables and wild fruit is too contemptible to deserve notice', wrote Watkins Tench in 1793 (230). In Charles 
Rowcroft's 1843 novel, Tales of the Colonies, or, The Adventures of An Emigrant, a character complains that 'the country furnishes nothing of itself: no animals, no fruits, no roots. Now I thought before I came here, there must be plenty of fruit in a warm climate; but, bless your heart, you may look a long time in the woods for anything to eat, I can tell you' (Rowcroft 23). Generalising from such observations, many writers at the end of the twentieth century perpetuated the view that '[s] urprisingly little attention was paid by the early colonists to the diet of the Aborigines, from whom they could have learned much about alternative food sources' (Ripe 18). Other commentators noted the colonists' general unwillingness 'to adapt ... to Aboriginal eating strategies' (Ryan, Edwards, and Occhipinti 317). According to Symons, 'we failed to incorporate a single indigenous food into anything resembling an agriculture and cooking appropriate to the environment' (11). Such conclusions are not altogether unjustified; the majority of Europeans did not embrace Aboriginal foods and foodways. Nevertheless, they ignore the accounts of extensive and often successful experimentation of many nineteenth-century settlers. Indeed, many early explorers owed their survival to the example of Aboriginal people; other settlers gratefully learnt from the indigenous inhabitants and adopted their eating practices; many others again tried the foods of the Aboriginal people simply out of curiosity and pronounced them good, even if certain of them were altogether too alien to be considered 'food'.

Though this early experimentation has been insufficiently acknowledged by general historians, it has not escaped the notice of those interested in bush foods and culinary history. In their guide, Wild Food in Australia, Cribb and Cribb attest to 'a few white men' taking 'an intelligent and even respectful interest in the race that was being displaced - explorers, missionaries, botanists, naturalists, government officials - they observed, they recorded, and fortunately in some cases they published' (13-14). Beckett, while agreeing that 'white settlers commercially exploited very few of the continent's existing food resources and on the whole disregarded the way the Aboriginals made use of them (in expressing either revulsion or patronising curiosity, and sometimes both at the same time)', nonetheless recognises that 'in the early days they did quite a lot of experimental fiddling themselves' (50). Culinary historian Bannerman concurs: '[f]rom the earliest days or white occupation, Australian native food resources were exploited on every plane of feeding - survival, nurture and feasting. ... However, bush foods also represented failure' (20).

Despite Tench's dismissal of the indigenous fruits and vegetables around Sydney Harbour, he and other European inhabitants had no hesitation accepting animal foods - fish, crabs, oysters and kangaroo. Tench's 1789 journal mentions the 'light horseman' or snapper, as well as 'bass, mullets, skates, soles, leatherjackets and many other species, all so good in their kind as to double our regret 
at their not being more numerous' (76). The self-evident similarities between antipodean and Northern Hemisphere seafood would have eliminated any obstacles to their consumption, even had hunger not been the prime motive. The kangaroo, on the other hand, was totally unprecedented, but its meat was red, its carcase was consistent with that of familiar domestic animals, and the example of Aboriginals confirmed its edibility. It may have been partly out of desperation that colonists readily accepted and appreciated kangaroo - and its near relatives, such as wallaby - in the earliest years of settlement, but its resemblance in both appearance and flavour to other familiar red meats such as beef, venison and hare must have been reassuring. 'We often killed kangaroos; they are very palatable, particularly the tail, which makes excellent soup,' reported Katherine Kirkland in western Victoria in the 1840s (201). 'Kangaroo steak is palatable enough if dressed in the same manner as veal cutlets or venison collops,' decreed Clement Hodgkinson in his 1845 report on the natural resources of the region from Port Macquarie to Moreton Bay, 'but the small pademella, if cooked in the same manner as hare, is undoubtedly excellent' (200-201).

Similarly, wild duck and other game birds were accepted without hesitationindeed, wild birds often took the place of scarce and expensive domesticated poultry. The intrepid Lady Franklin, wife of the governor of Tasmania, gladly ate a variety of local fauna - blue duck, black swan, cockatoo and even 'magpye' on her travels overland from Port Philip Bay to Sydney in 1839 (Russell 41, $51,58)$, while Katherine Kirkland relished native fowl as a change from the monotony of mutton (Anderson 201). Mrs Maclurcan, manager of the Criterion hotel in Townsville at the end of the nineteenth century, also considered native birds appropriate substitutes for European species. In her 1898 cookbook, Mrs Maclurcan's Cookery Book: A Collection of Practical Recipes, Specially Suitable for Australia, she gave a recipe for roast scrub turkey - 'a small bird, not much larger than a wild duck, with a breast like a pheasant and flesh as white. I have often served it as pheasant and people have not known the difference' (Maclurcan 386).

Such was the enthusiasm of Europeans for native game that in the early 1860s a selection of Australian fauna was offered, and eventually sent, to the Acclimatisation Society of the United Kingdom. Chosen both for their exoticism and economic potential, they included the brush turkey (also known as the scrub or bush turkey), 'one of the best birds for the table', in the opinion of Clement Hodgkinson, together with the wonga wonga pigeon, bustard and kangaroo (205). 'Imagine our dovecotes full of these birds [wonga wonga pigeons]', wrote a member of the Society, 'selling, let us hope, at 1s. or 14d. a couple' ('Acclimatisation' 7). Praised as the 'queen of the pigeon tribe ... combining in the most delicate proportion the flavour of the pheasant and the 
grouse', the wonga wonga pigeon was considered one of the best birds in the world for eating ('Acclimatisation' 7). Clement Hodgkinson described its flesh as 'quite white and very rich 'and goes on to comment that 'this bird has often furnished my bush table in the wilds of Australia with a 'plat' not to be despised by the most fastidious gourmand' (206). Mrs Maclurcan included a recipe for roast wonga pigeon in her cookbook, and Godfrey Charles Mundy relished 'a delicate wing of the wonga-wonga pigeon' with bread sauce when he dined with the acting governor of New South Wales in 1846 (Mundy 12).

Even the most unfamiliar and unlikely fauna became the subject of culinary experimentation. Inspired by curiosity and a bold spirit of adventure, Louisa Meredith and the resourceful Mina Rawson attempted to cook and eat magpie, ibis, kangaroo rat, flying fox, bandicoot, echidna and wombat. According to Meredith, echidna was similar to sucking pig though 'too rich for most palates', while wombat was 'fatter and coarser, with a strong, rank flavour' (My Home 255-257). Mrs Rawson appreciated bandicoot, soaked in vinegar then stuffed with sweet potatoes and onion and roasted or boiled. In her list of 'Things to be Remembered' she decreed onion sauce to accompany both boiled rabbit and boiled bandicoot (Antipodean 19). Flying fox, she wrote, 'are excellent eating ... once get rid of the wings and skin and you will hardly know the flesh from pork. I have had people eat it at my table without ever guessing what it was, and they have even complimented me upon the flavour of my chicken pie.... I cut them up, along with an onion, and seasoned with all sorts of herbs, and stewed them for a couple of hours, then turned them into a pie dish and covered with a good paste. Curried, you would not know flying fish from pork' (Cookery Book 32). Despite their best efforts of these trail-blazers, however, some game resisted attempts to be made palatable; Mrs Rawson's cautious appraisal of ibis is hardly a recommendation; 'This bird has a very objectionable odour, and consequently is little used, but the smell is confined solely to the feathers and skin. ... If baked, he requires to be well seasoned and constantly basted, as the flesh is rather dry and it is also very dark' (Australian Enquiry Book 41). As for magpie, 'some persons like these birds when cooked', wrote Louisa Meredith, 'but, after exhausting all my culinary skill upon them in roasts, stews, curries and pies, I have finally given them up as not cookable, or rather as not relishable when cooked' (My Home 237).

Acceptance of indigenous animals and birds was facilitated by their resemblance to familiar species in the northern hemisphere, but another reason why they were so willingly embraced is that they represented meat, and meat was the most prestigious - indeed, the essential-element of a nineteenth-century dinner. The lack of hesitation in experimenting with black duck and bandicoot contrasts with a certain wariness in relation to plant foods. Nevertheless, many hardy pioneers were prepared to sample selected plant parts, often following the 
example of the Aboriginal inhabitants. In western Victoria, Richard Skilbeck praised the Marsh Flag, a species of bulrush 'of which immense quantities exist in the interior'. Its roots could be dried and ground to yield 'an excellent and nutritious arrowroot' while the young new shoots, 'cut and tied up in bundles and dressed in the same manner as asparagus ... forms a most delicate vegetable and can hardly be distinguished from the former plant either in flavor or appearance' (McCorkell 151). Katherine Kirkland harvested the tubers of the yam daisy or murnong/murrnong/maranong (Microseris scapigera), writing: 'Maranong is a root found in the ground: it is white, and shaped like a carrot, but the taste is more like a turnip. The leubras [Aboriginal women] dig for it with long pointed sticks, which they always carry in their hands. I have often eaten maranong; it is very good; and I have put it in soup for want of better vegetables, before we had a garden' (Anderson 191). Early settlers in the Adelaide Hills similarly relished murnong roots (Low 104).

In northern Queensland, Mrs. Rawson enjoyed the bush yams that 'grow at the root of a vine, and are not unlike sweet potatoes when unearthed, but have a far nicer flavour, more nutty'. She also ate the fresh new shoots of the rough-leaved native fig and considered them an excellent substitute for spinach (Rawson, Cookery Book 34). In more temperate regions the fleshy leaves of New Zealand spinach (Tetragonia tetragonioides, a native of Australia as well as of New Zealand) served the same purpose; in 1856 the Western Australian Horticultural Society recommended sowing New Zealand spinach in place of the temperamental English spinach ('Horticultural Society' 3). Writing in the pages of the Brisbane Courier in 1866, 'L.L.' praised the native plant as superior to the domesticated variety: 'there is a softness and mildness in its taste (added to its flavor, which resembles that of common spinach) in which it has an advantage over that herb. ... In my own house ... it has been a welcome dish for the last three years' (5). Pigweed (Portulaca oleracea) was another widespread and widely used green vegetable. According to 'An Overlander', writing in the Argus in 1886, it 'really makes a rather good salad. It has a taste something like sorrel' (10). In her Antipodean Cookery Book Mrs Rawson gave recipes for pigweed, boiled and served with butter or baked with cheese or made into a salad (Antipodean 52-53).

The strangeness of the miniscule fruit of many indigenous plants was often a barrier to their acceptance and consumption, though in comparison with leaves and roots there seems to have been a greater readiness to accept native fruits, especially when domesticated in the form of jam or a preserve of some kind. In Queensland, native limes (Microcitrus spp.) - 'a little fruit about the size of a large gooseberry, but in colour, taste, smell and shape exactly like a small lemon' (Henning 147) were made into jam; rosellas (Hibiscus heterophyllus) were transformed into jelly, jam and pickle; and Mrs Rawson gathered nightshade 
berries (Solanum americanum) which, despite their 'peculiar flavour eaten raw' could be 'converted into tarts, or jam ... as nice as any of the more familiar berry jams' (Cookery Book 91-92). Early settlers in South Australia organised late winter expeditions to the Barossa Ranges to gather native currants to preserve as a dark, tart jam ('Barossa' 3). In the 1860s Rachel Henning made tarts of wild raspberries (Rubus spp.), one of the most familiar fruits to the early settlers (Henning 231). Relatively common in tropical and subtropical regions, its habitat extended as far as Tasmania where it was described as the island's best native fruit. Though lacking the sweetness and intensity of the domesticated variety, despite being closely related and of similar appearance, it was considered by Louisa Meredith to be 'a pleasant acquaintance on a warm day' (Bush Friends 105). She described another native fruit, the kangaroo apple (Solanum aviculare), as 'extremely sweet and luscious' (Bush Friends 25).

At the most extreme end of the edible scale, reptiles and insects might have been less readily accepted and consumed than kangaroo or quail, but nor were they totally rejected. Clement Hodgkinson reported that he had tasted a variety of reptiles:

although nothing but the most extreme hunger could make me conquer my aversion, so as to dine on then, I must nevertheless own, that not one of them possessed any disagreeable taste. The flesh of the black snake in particular was rich and juicy, somewhat resembling in flavour the flesh of a sucking pig, whilst that of the guana was whiter and drier, and more approximated to fowl. (224)

Mrs. Rawson relished large brown grasshoppers, 'edible and very good when parched' (Antipodean 54), and Lady Franklin noted in her 1839 journal that 'the Corporal has eaten both moths \& grubs', referring to Bogong moths (Russell 54). Witchetty grubs, a delicacy amongst Aboriginal people, were also eaten. According to 1840s pioneer Annie Baxter, one of her stockmen, Jack, was not reluctant to pop a witchetty grub in his mouth, preferring to eat them uncooked 'in the savage, undressed state'. Nor was he alone; a gentleman of Mrs Baxter's acquaintance ate them roasted, saying they tasted like filberts or hazelnuts (Baxter 55), and the redoubtable Mrs Rawson commended them:

As a matter of fact, there is nothing nasty or disgusting in these soft white morsels, any more than there is in an oyster. It is all a matter of taste. Both are often swallowed alike; for my own part, I prefer the grubs parched before eating. If done over a clear fire, on a piece of tin or a flat stone, they are delicious. I have never tried them in a curry, but feel sure they would be excellent. (Antipodean 54) 
While many writers commended indigenous foods for personal sustenance and dietary variation, other nineteenth-century pioneers looked to their commercial potential. As early as 1829 a correspondent to the Hobart Town Courier identified a number of plant foods 'as well deserving the attention of the naturalist and physician', including the fungus known as 'native bread' (identified as Tuber cibarium). 'The Blacks of Van Diemen's land are exceedingly fond of this fungus', he added, 'and some of our countrymen subsisted chiefly on it for several days when exploring the country for the hostile natives' (Hobart Town Courier 2). Around the middle of the nineteenth century French political refugee Anthelme Thozet actively investigated the potential usefulness of native flora, noting that 'Our pioneer explorers and travellers ... often die of hunger although surrounded by abundance of native vegetable food in the very spot where the aborigines find all the luxuries of their primitive method of life, and not a few unacquainted with the preparation which several of the deleterious plants require, lose their lives in venturing to use them' (5). Jams, jellies and other preserves made from native fruits were sent to the 1855 Exposition Universelle in Paris ('New South Wales' 3). Near the end of the nineteenth century, Queensland horticulturists urged experimentation with native fruits in order to assess their practicality and value ('Our Indigenous Fruits' 1161) and attempts were made to cultivate the native raspberry and cross it with the English variety to improve its flavour.

These and a great many other accounts make it amply clear that indigenous foods, of both animal and plant origin, were neither systematically ignored by early colonists, nor excluded from the category of potential food. Driven by curiosity or necessity or both, nineteenth-century Europeans sampled and experimented with an extraordinarily wide range of animals and plants which formed part of the normal diet of the Aboriginal people. The necessary first step, however, was to try the new foods with an open mind and open palate, and this almost always necessitated some interaction with Aboriginal men and women, as Katherine Kirkland indicated. Even though the language of each might have been incomprehensible to the other, some communication may have taken place, and from this came a measure of understanding and appreciation. Numerous writers specifically acknowledged the assistance of the indigenous inhabitants as guides and instructors. 'Whatever the blacks eat the whites may safely try', advised Mrs. Rawson (Antipodean 54), who admitted: 'Speaking personally, I am beholden to the blacks for nearly all my knowledge of the different edible ground game' (Antipodean 54). 'It is a mistake to imagine the blacks of this country are foul feeders', she added; 'by nature and instinct they are hunters, and what they use for food you may be quite sure is the best and most wholesome' (Cookery Book 33). Robert Dawson similarly appreciated the practical wisdom of the indigenous people and showed an enlightened interest in their foods and foodways, writing in 1830: 
'He [the Australian Aboriginal] can eat either the kangaroo or the lizard, the oyster or the grub, all of which exist in the greatest abundance around him. We can join him in the kangaroo and oyster, while we recall at the lizard and the grub. Where is the difference? The latter are as tender and as wholesome as the former. The black eats the grub without cooking; do we not do the same with the oyster. ... I would therefore recommend those who place the Australian natives on the level of brutes, to reflect well on the nature of man in his untutored state in comparison with his more civilised brother, indulging in endless whims and inconsistencies, before they venture to pass a sentence which a little calm consideration may convince them to be unjust. (152)

Without diminishing the achievements of these gastronomic pioneers, it should be acknowledged that those who willingly experimented with the food resources of the bush and lived to tell the tale represented a select few, those educated colonists with enquiring minds - the same ones who wrote the letters, journals and memoirs which testify to their adventures. It is impossible to know the extent of this experimentation nor whether it was shared by most of the educated and curious. Despite the enthusiasm of the experimenters, ignorance or disdain of natural resources seems to have prevailed and the majority of the population was probably more likely to share the views of Louisa Meredith's servants who 'looked upon our eating kangaroo as something absolutely monstrous, and turned away in horror at the thought of partaking what they expressively designated as "just a weird beast!" (My Home 252-253). Nor were the less educated alone in turning up their noses at native produce. In Sydney in the 1840s, again according to Mrs Meredith, local seafood was not considered 'a proper dish for a dinner-party' (Notes and Sketches 44).

Nevertheless, the acceptance, albeit limited, of native foods by European settlers in nineteenth-century Australia depended on their transformation by means of familiar culinary practices. Mrs Rawson seemed to believe that there was no ingredient that could not be accommodated by curry. European reliance on the experience and knowledge of Aboriginal people did not go so far as adopting their traditional cooking methods; rather, it was limited to determining what was edible, in both a literal and cultural sense, and to borrowing some preliminary preparation techniques. Despite sometimes enthusiastic commendation of Aboriginal cooking techniques there is no evidence that they migrated into European kitchens:

we have often partaken of a choice cutlet of turtle with our sable brethren, from a five-hundred-weight animal, cooked in its own shell; and we can aver that it was far more savoury than the spiced dishes John Bull has served up from calipash and calipee, in the shape of turtle- 
steaks and turtle-soup. The fact is, the chef de cuisine at the Mansion House might add a recipe or two worth knowing to his cookery-book from these natural gourmands. (Mossman and Banister 294-295)

Aboriginal culinary practices were recorded and assessed, even praised, but they were rarely accepted, and only through absolute necessity rather than by preference. Over time the pioneers' need to rely on natural resources, whether kangaroo or wild duck or native greens, diminished, and with this, the opportunity to engage with Aboriginal foods and foodways. Writing in the Brisbane Courier in 1872, 'G.' lamented the opportunities missed through lack of interest in the food potential of the bush 'which has only to be known to be valued, and which, when prejudices are removed, might be thankfully used' (7). At the same time 'G.' hoped that a greater understanding and appreciation of Aboriginal foodways might generate 'a little kindly feeling for the blacks, who are by no means so black as they are painted' (7).

Colonial experimentation required indigenous ingredients to be culturally appropriated, plucked from one culture and incorporated into another so that the foreign became familiar. The agent of transformation, as Lévi-Strauss, Fischler, Rozin and Rozin and many others have pointed out, is cuisine; preparing the unknown and potentially risky ingredient according to a familiar technique and flavouring it with familiar seasonings facilitates its acceptance. According to Lévi-Strauss, cooking is situated between nature and culture and ensures the necessary articulation of one with the other; it transforms the raw, in the realm of nature, to the cooked, a cultural product (405). In nineteenth century Australia, essentially only one culinary model - the English — was available, yielding dishes such as boiled bandicoot, parrot pie and curried wattle birds.

In the twentieth century, as Australians became more urbanised and more distanced from the origins of their foods, so they became estranged from native ingredients. Only in relatively remote parts of the country did any appreciation of foods such as kangaroo and quandong persist. In the more densely populated coastal regions, much of the native Australian bush was razed, and with it the flora and fauna as well as the hunting and gathering practices and knowledge of both the indigenous inhabitants and the early Europeans. The introduction of sheep to Victoria destroyed the murnong, once a staple of the indigenous people (Low 108). Certain plants and animals, including the wonga wonga pigeon, are now protected. In these circumstances, it is hardly surprising that indigenous foods had virtually no relevance to most settler Australians. Nevertheless, from the 1980s there has been a revival of interest in Australian 'bush foods' - a category today typically limited to foods of plant origin — which roughly coincides with the celebrations of Australia's bicentenary and debate about national identity. The motivation of necessity has long disappeared but, as in the nineteenth century, curiosity might still kindle a desire to sample indigenous foods. Today, 
as Craw notes, the emphasis is on 'the gastronomic characteristics and 'gourmet' quality of such ingredients' (42) which are 'inserted into a 'modern Australian' cuisine' (Craw 54) to yield dishes such as Tetragon, macadamia and bunya nut pesto and Witjuti grubs with peanut sauce (Bruneteau 122, 54). Modern experimentation and acculturation has generally been in the kitchens of nonAboriginal chefs whose preferred models are Mediterranean and Asian cuisines, but Aboriginal chefs such as Mark Olive are increasingly contributing to the development of dishes using indigenous ingredients.

Using cuisine as the agent of transformation, as the means to make the unfamiliar familiar, echoes the example of the early pioneers who incorporated native foods into their familiar English model. Nonetheless, two important features distinguish the nineteenth-century experimentation from the practices of today. In the nineteenth century, indigenous ingredients were cooked in home kitchens and formed the main part of a family meal, or at least a significant component; in the twenty-first century they are processed in commercial kitchens, most often into sauces, chutneys and other condiments, seasonings and preserves, and constitute a mere accessory to the meal. Further, the actual proportion of indigenous ingredients in these commercial products can be extremely small (Craw 47). Bannerman refers to this way of incorporating indigenous foods as commodification (31), putting an economic value on natural resources and marketing them as representative of Australia.

If the goal is not merely occasional acceptance but rather the co-opting of indigenous ingredients 'as national symbols' (Craw 48), or even the more ambitious one of making indigenous ingredients the base of a national cuisine, then greater efforts need to be made to harness the transforming power of cuisine. Only if they are regularly and widely consumed can indigenous plants and animals - which include the familiar fish, crustaceans and shellfish from Australian waters as well as the lesser known plant foods - be considered part of Australian food culture, understood as not only what is eaten by a significant proportion of the population but also the common preparation, cooking and eating practices and the ideas and values associated with these. Only if they are regularly and widely consumed can their consumption symbolise Australianness; as Bannerman notes, Australian cuisine is the cuisine Australians experience' (36).

If indigenous foods are to be a genuine part of Australian food culturewhich implies their presence at backyard barbecues as well as sophisticated restaurants - they must be mainstreamed into the supermarkets where approximately four out of every five consumers buy their household's supplies. Bannerman points out that it is only with the support of the food industry that indigenous foods can find a place in mainstream Australian cooking (36), but instead of occupying just the condiment periphery they should capture territory 
in the ever-increasing range of convenience foods, such as the packets and jars of stir-fry and simmer sauces and the marinated meats. The Adelaide company, Bush Tucker Ice Cream, offers an example, producing icecream flavoured with indigenous ingredients such as wattleseed, Davidson's plum, quandong, Kakadu plum and desert lime (Bush Tucker Ice Cream). Similarly, indigenous herbs and fruits should become as ubiquitous as mint and parsley in backyard gardensand perhaps mandatory in school kitchen gardens. Some species, such as native thyme and lemon myrtle, are already commercially available, if not common, but their diffusion should be expanded; further research may be necessary to ensure that native plant species can be successfully grown in a range of environments. One of the most exciting recent introductions is the range of unique limes - the Australian Sunrise, Australian Blood and Australian Outback limes-all crosses between conventional and native citrus developed by CSIRO Plant Industry at Merbein, Victoria (CSIRO).

The relatively recent revival of interest in indigenous foods explains their rarity on our daily tables, yet the potential for them to move from a niche to a popular market is enormous. The processes of experimentation and acculturation have only just begun. The challenge facing bush foods today, apart from adequate supplies and accessibility, is to become a genuine part of Australian culture and their consumption an identifiable component of Australian identity, in the same way that pasta and pizza are associated with Italian identity. This requires their widespread acceptance and a move from the novelty and niche categories to everyday fare. While indigenous ingredients need to conform to today's culinary styles and tastes to have a role in and relevance to contemporary Australian food culture, this adaptability should not be at the expense of history and mythology. If they are to join the ranks of foods which symbolise Australian-ness, they should not only be valued for their present-day ability to add a distinctive flavour to a particular dish but also for their past, for the stories associated with their role in traditional Aboriginal culture as well as with nineteenth-century experimentation.

Barbara Santich teaches food history and culture and food writing in the Graduate Program in Food Studies at the University of Adelaide. Her new book on Australia's gastronomic heritage will be published in early 2012. 


\section{Works cited}

Alexander, Stephanie. The Cook's Companion. Ringwood, Vic: Viking, 1996.

Anderson, Hugh. Flowers of the Field: A History of Ripon Shire Together with Mrs Kirkland's Life in the Bush, from Chambers's Miscellany. 1845. Melbourne: Hill of Content, 1969.

An Overlander. 'A Trip through the Northern Territory.' Argus 3 May 1886: 10.

'Acclimatisation.' Argus 31 July 1862: 7.

Bannerman, Colin. 'Indigenous Food and Cookery Books: Redefining Aboriginal Cuisine.' Culinary Distinction. Ed. Emma Costantino and Sian Supski. Perth: API Network/Australia Research Institute, 2006. 19-36.

'Barossa.' South Australian Advertiser. 28 August 1860: 3.

Baxter, Annie. Memories of Tasmania and of the Macleay River and New England Districts of New South Wales and of Port Fairy in the Western District of Port Phillip, 1834-1848. Adelaide: Sullivan's Cove, 1980.

Beckett, Richard. Convicted Tastes: Food in Australia. Sydney: George Allen \& Unwin, 1984.

Bruneteau, Jean-Paul. Tukka: Real Australian Food. Sydney: Angus \& Robertson, 1996.

Bush Tucker Ice Cream. <http://www.bushtuckericecream.com.au/>. Accessed 25 May 2010.

Cherikoff, Vic. Uniquely Australian: The Beginnings of an Australian Bushfood Cuisine. Sydney: Bush Tucker Supply Pty Ltd, 1992.

Craw, Charlotte. 'The Flavours of the Indigenous: Branding Native Food Products in Contemporary Australia.' Sites: New Series 5.1 (2008): 41-62.

Cribb, A.B. and J. W. Cribb. Wild Food in Australia. Sydney: Book Club Associates, 1975.

CSIRO Plant Industry. 'A Taste of the Outback.' 25 May 2010. <http://tinyurl. com/626rf25>. Accessed 26 October 2011.

Dawson, Robert. The Present State of Australia: A Description of the Country. London: Smith, Elder \& Co, 1830.

Fischler, Claude. 'Food Habits, Social Change and the Nature/Culture Dilemma' Social Science Information 19 (1980): 937-953. 
'G.' 'Black cuisine v. White cookery.' Brisbane Courier, 4 May 1872: 7.

Henning, Rachel. The Letters of Rachel Henning. Ed. David Adams. Ringwood, Vic: Penguin, 1988.

Hobart Town Courier 7 February 1829: 2.

Hodgkinson, Clement. Australia, from Port Macquarie to Moreton Bay. London: T. and W. Boone, 1845.

'Horticultural Society' Perth Gazette and Independent Journal of Politics and News 10 October1856: 3.

L.L. 'The Tetragonia Expansa.' Brisbane Courier 20 Jan. 1866: 5.

Lévi-Strauss, Claude. L'Origine des Manières de Table. Vol. III of Mythologiques. Paris: Plon, 1968.

Low, Tim. Bush Tucker: Australia's Wild Food Harvest. Sydney: Angus \& Robertson, 1992.

Maclurcan, Mrs. Hannah. Mrs Maclurcan's Cookery Book: A Collection of Practical Recipes, Specially Suitable for Australia. Townsville, Qld.: T. Willmett, 1898.

McCorkell, H. A., ed. The Diaries of Sarah Midgley and Richard Skilbeck: A Story of Australian Settlers, 1851-1864. Melbourne: Cassell, 1967.

Meredith, Mrs. Charles. Notes and Sketches of New South Wales during a Residence in the Colony from 1839 to 1844. 1844. Sydney: Ure Smith in Association with the National Trust of Australia (NSW), 1973.

Meredith, Louisa. My Home in Tasmania, During a Residence of Nine Years. London: John Murray, 1852.

Meredith, Louisa. Bush Friends in Tasmania: Native Flowers, Fruits, and Insects, Drawn from Nature, with Prose Descriptions and Illustrations in Verse. London: Macmillan, 1891.

Mossman, Samuel and Thomas Banister. Australia Visited and Re-Visited: A Narrative of Recent Travels and Old Experiences in Victoria and New South Wales. 1853. Dee Why: Ure Smith, 1974.

Mundy, G.C. Our Antipodes; or, Residence and Rambles in the Australasian Colonies. 1852. London: Bentley, 1855.

'New South Wales Department of the Paris Exhibition.' Sydney Morning Herald 21 Dec. 1855: 3. 
'Our Indigenous Fruits.' The Queenslander, 19 Dec. 1891: 1161.

Rawson, Mrs. Lance. [1895] The Antipodean Cookery Book and Kitchen Companion. Kenthurst, NSW: Kangaroo Press, 1992.

-. [1895] The Australian Enquiry Book of Household and General Information: A Practical Guide for the Cottage, Villa and Bush Home: Recipes and Information Upon Everything and for Everybody. Kenthurst, NSW: Kangaroo Press, 1985.

- Mrs. Lance Rawson's Cookery Book and Household Hints. Rockhampton: William Hopkins, 1890.

Ripe, Cherry. Australia the Beautiful Cookbook. Sydney: Cumulus, 1995.

Rowcroft, Charles. [1843] Tales of the Colonies; or, the Adventures of an Emigrant. London: Smith, Elder, 1847.

Rozin, Elizabeth, and Paul Rozin. 'Culinary Themes and Variations.' Natural History 90 (1981): 6-14.

Russell, Penny. This Errant Lady: Jane Franklin's Overland Journey to Port Phillip and Sydney, 1839. Canberra: National Library of Australia, 2002.

Symons, Michael. One Continuous Picnic: A History of Eating in Australia. Adelaide: Duck Press, 1982.

Tench, Watkin. 1788: Comprising A Narrative of the Expedition to Botany Bay and A Complete Account of the Settlement at Port Jackson. Ed. Tim Flannery. Melbourne: Text Publishing, 1996. 